\title{
Supernumerary Teeth: A Retrospective Cross-Sectional Study from Palestine
}

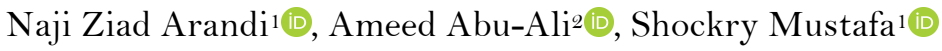

\begin{abstract}
${ }^{1}$ Department of Conservative Dentistry and Prosthodontics, Faculty of Dentistry, The Arab American University, Jenin, Palestine.

2Department of Maxillofacial Surgery and Radiology, Faculty of Dentistry, The Arab American University, Jenin, Palestine.
\end{abstract}

Author to whom correspondence should be addressed: Dr. Naji Ziad Arandi, Assistant Professor, Department of Conservative Dentistry and Prosthodontics, Faculty of Dentistry, The Arab American University, Jenin, Palestine. Phone: +97 2598126111. E-mail: naji.arandi@aaup.edu.

Academic Editors: Alessandro Leite Cavalcanti and Wilton Wilney Nascimento Padilha

Received: 03 July 2019 / Accepted: 22 December 2019 / Published: 20 January 2020

How to cite this article: Arandi NZ, Abu-Ali A, Mustafa S. Supernumerary teeth: a retrospective cross-sectional study from Palestine. Pesqui Bras Odontopediatria Clín Integr. 2020; 20:e5057. https://doi.org/10.1590/pboci.2020.029

\begin{abstract}
Objective: To investigate the prevalence and characteristics of supernumerary teeth among patients attending the students' dental clinics at the Faculty of Dentistry of the Arab American University, Jenin, Palestine. Material and Methods: This is a descriptive, cross-sectional, retrospective study of 1970 digital panoramic radiographs of patients, age ranging between 12 and 50 years. The radiographs and dental records were reviewed for supernumerary teeth. For each patient with supernumerary teeth, were recorded the demographic variables, number, location, eruption status, type, and morphology, the developmental stages. Descriptive statistics were performed and results were tabulated. Results: Supernumerary teeth were detected in 17 subjects $(0.86 \%)$, of which 13 were males and 4 were females with a male to female ratio of $3.25: 1$. Of the 17 patients, $64.7 \%$ had one supernumerary tooth while the others had two. The majority $(78.3 \%)$ of the supernumeraries were located in the maxilla. Around $56.5 \%$ of the supernumeraries found in this study were located in the premaxilla. Half of the supernumeraries $(52.2 \%)$ were erupted, and $47.8 \%$ were impacted. Mesiodens was the most frequently seen supernumerary teeth followed by distomolars and premolars. Most of the supernumeraries were fully developed, while $21.7 \%$ displayed only crown formation. Conclusion: The prevalence of supernumerary teeth in the study sample was found to be $0.86 \%$ and the most frequent type was mesiodens. Supplemental morphology was found to be the most common form of supernumerary teeth.
\end{abstract}

Keywords: Prevalence; Cross-Sectional Studies; Tooth Abnormalities; Tooth, Supernumerary. 


\section{Introduction}

Developmental dental anomalies are marked deviations from the normal presentation of the primary or permanent dentition. Local, as well as systemic factors, may be responsible for these disturbances. The influence of these factors may begin before or after birth; hence, deciduous or permanent teeth may be affected. Developmental dental anomalies consist of a wide range of disorders, including changes in the number, morphology, eruption, and size of teeth. These anomalies can complicate dental treatments, such as root canal therapy or tooth extraction, and can induce malocclusion, and aesthetic problems.

Anomalies resulting in a variation in the number of teeth include hypodontia (decreased number of teeth) and hyperdontia (teeth in excess of the normal dental formula; supernumerary teeth) and both can be found in almost any region of the dental arch either unilaterally or bilaterally and in the mandible and/or maxilla. The prevalence of hypodontia has been reported to be more common than hyperdontia [1-7]. The prevalence of hyperdontia in the permanent dentition has been reported by various studies to fall in the range of 0.04 to $2.7 \%[1-10]$.

Supernumerary teeth may be single or multiple. Cases of multiple (five or more) supernumerary teeth not associated with other systemic diseases or syndromes are rare and when present, the most common site affected is the mandibular premolar region [11]. Supernumerary teeth are more frequently observed in permanent dentition than in deciduous dentition with more frequency for the upper arch than the lower arch with a strong predilection for the premaxilla [12].

The classification of supernumerary teeth is usually based on their morphology, together with their location in the dental arches [13]. According to their locations, supernumeraries may be categorized into four types; mesiodens, paramolar, distomolar and parapremolar and into two types according to their morphology (form); rudimentary and supplemental. Rudimentary (or dysmorphic) defines teeth of abnormal shape and smaller size, including conical, tuberculate and molariform types, while supplemental teeth (or eumorphic) are of normal shape and size resembling a particular tooth from the normal dentition. Supernumerary teeth may also be classified according to their orientation (vertical or normal, inverted and horizontal) or according to their position (buccal, palatal and transverse) [14].

Complications associated with supernumerary teeth include crowding, disturbed eruption, or retention of teeth, delayed or abnormal root formation in permanent teeth, and cyst. However, some cases of supernumerary teeth may be asymptomatic and detected incidentally during a routine radiographic examination or when normal tooth eruption is delayed or fails.

The literature on supernumerary teeth reveals significant discrepancies between the results of studies analyzing the prevalence of supernumerary teeth in various populations [5,7,10,15-19]. No study has been done to assess the prevalence and occurrence of supernumerary teeth in Palestine. The aim of this study was to determine the prevalence of supernumerary teeth and investigate its characteristics in the Palestinian population.

\section{Material and Methods}

Study Design and Sample

This study comprises data from digital panoramic radiographs of 1970 patients who attended the student's clinics at the Faculty of Dentistry of the Arab American University in Palestine between January 2018 and February 2019. 


\section{Data Collection}

Digital panoramic radiographs were taken by using Sirona Orthophos XG digital X-ray unit (Dentsply Sirona Inc., Charlotte, NC, USA). Radiographs were examined retrospectively to detect the presence of any supernumerary teeth. All radiographs were evaluated by two trained dentists at the same time. For each patient with supernumerary, teeth were recorded the demographic variables (including age, sex), number, location (maxilla or mandible), position, type, eruption status (erupted or impacted) and morphology, namely conical, tuberculate, or supplemental. Odontomas were excluded from the study since they are not universally considered to be supernumerary teeth, the developmental stages were described as a fully developed crown, fully developed crown with root under formation, and fully developed supernumerary teeth.

Data Analysis

Data were analyzed using Statistical Package for the Social Sciences (SPSS version 16.0 IBM, Armonk, NY: IBM Corp, USA). Descriptive statistics were used to calculate the absolute and relative frequencies.

Ethical Aspects

This research project was approved by the IRB Committee of the Faculty of Dentistry, The Arab American University.

\section{Results}

In 17 of the 1970 patients $(0.86 \%) 23$ supernumerary teeth were found (Table 1$)$. The male $(n=13)$ to female $(n=4)$ ratio was 3.25:1. Eleven patients $(64.7 \%)$ had one supernumerary tooth, and $6(35.3 \%)$ patients had two supernumerary teeth. None had more than two supernumerary teeth.

Mesiodens were the most frequently seen supernumerary teeth (26.1\%) followed by distomolars (21.7\%), premolars (21.7\%), lateral incisors (17.4\%) and canines (13.0\%). Eighteen (78.3\%) supernumeraries were in the maxilla, and $5(21.8 \%)$ in the mandible (3.6:1). Thirteen $(56.5 \%)$ were in the premaxillary region.

Twelve $(52.2 \%)$ of all supernumerary teeth were erupted and $47.8 \%(n=11)$ were impacted. All distomolars and mandibular premolars were impacted. Maxillary mesiodens had an impaction rate of $60 \%$. On the other hand, only 1 of 3 mandibular canines was impacted while all maxillary premolars, mandibular mesiodens and lateral incisors were erupted. Most supernumerary teeth were in a vertical position (69.6\%). Around $8.7 \%$ were mesioinclined, $8.7 \%$ distoinclined, and $13.0 \%$ horizontally positioned. No supernumerary had an inverted position.

Table 1. Distribution and characteristics of supernumerary teeth.

\begin{tabular}{|c|c|c|c|c|c|c|c|c|c|c|}
\hline \multirow{2}{*}{ Variables } & \multirow{2}{*}{$\begin{array}{c}\text { Mx } \\
\text { Mesio } \\
\text { N }\end{array}$} & \multirow{2}{*}{$\begin{array}{c}\text { Mn } \\
\text { Mesio } \\
\text { N } \\
\end{array}$} & \multirow{2}{*}{$\begin{array}{c}\mathbf{M x} \\
\text { Lateral } \\
\mathrm{N}\end{array}$} & \multirow{2}{*}{$\begin{array}{c}\text { Mx } \\
\text { Canine } \\
\mathrm{N}\end{array}$} & \multirow{2}{*}{$\begin{array}{c}\text { Mx } \\
\text { Premolar } \\
\text { N }\end{array}$} & \multirow{2}{*}{$\begin{array}{c}\text { Mn } \\
\text { Canine } \\
\text { N }\end{array}$} & \multirow{2}{*}{$\begin{array}{c}\text { Mn } \\
\text { Premolar } \\
\text { N }\end{array}$} & \multirow{2}{*}{$\begin{array}{c}\text { Disto } \\
\mathrm{N}\end{array}$} & \multicolumn{2}{|c|}{ Total } \\
\hline & & & & & & & & & $\mathrm{N}$ & $\%$ \\
\hline \multicolumn{11}{|l|}{ Sex } \\
\hline Male & 3 & 0 & 2 & 0 & 2 & 2 & 1 & 3 & 13 & 76.5 \\
\hline Female & 1 & 1 & 1 & $\mathrm{O}$ & 0 & $\mathrm{O}$ & $\mathrm{O}$ & 1 & 4 & 23.5 \\
\hline \multicolumn{11}{|l|}{ Number } \\
\hline Single & 3 & 1 & 2 & $\mathrm{O}$ & 1 & 1 & o & 3 & 11 & 64.7 \\
\hline Double & 1 & O & 1 & & 1 & 1 & 1 & 1 & 6 & 35.3 \\
\hline \multicolumn{11}{|l|}{ Region } \\
\hline Maxilla & 5 & - & 4 & $\mathrm{O}$ & 3 & - & - & 5 & 18 & 78.3 \\
\hline
\end{tabular}




\begin{tabular}{|c|c|c|c|c|c|c|c|c|c|c|}
\hline Mandible & - & 1 & o & $\mathrm{O}$ & - & 3 & 2 & $\mathrm{O}$ & 5 & 21.7 \\
\hline \multicolumn{11}{|l|}{ Eruption Status } \\
\hline Erupted & 2 & 1 & 4 & 0 & 3 & 2 & o & O & 12 & 52.2 \\
\hline Unerupted & 3 & $\mathrm{O}$ & $\mathrm{O}$ & $\mathrm{O}$ & $\mathrm{O}$ & 1 & 2 & 5 & 11 & 47.8 \\
\hline \multicolumn{11}{|l|}{ Position } \\
\hline Vertical & 2 & $\mathrm{O}$ & 4 & $\mathrm{O}$ & 3 & 2 & o & 5 & 16 & 69.6 \\
\hline Horizontal & 2 & O & $\mathrm{O}$ & 0 & 0 & 1 & $\mathrm{O}$ & O & 3 & 13.0 \\
\hline \multicolumn{11}{|l|}{ Type } \\
\hline Mesioangular & 1 & $\mathrm{O}$ & $\mathrm{O}$ & $\mathrm{O}$ & $\mathrm{O}$ & $\mathrm{O}$ & 1 & $\mathrm{O}$ & 2 & 8.7 \\
\hline Distoangular & $\mathrm{O}$ & 1 & o & $\mathrm{O}$ & o & $\mathrm{O}$ & 1 & $\mathrm{O}$ & 2 & 8.7 \\
\hline \multicolumn{11}{|l|}{ Morphology } \\
\hline Supplemental & O & $\mathrm{O}$ & 4 & $\mathrm{O}$ & 3 & 1 & 2 & $\mathrm{O}$ & 10 & 43.5 \\
\hline Conical & 5 & 1 & $\mathrm{O}$ & $\mathrm{O}$ & $\mathrm{O}$ & 2 & $\mathrm{O}$ & $\mathrm{O}$ & 8 & 34.8 \\
\hline Tuberculate & $\mathrm{O}$ & $\mathrm{O}$ & $\mathrm{O}$ & $\mathrm{O}$ & $\mathrm{O}$ & $\mathrm{O}$ & $\mathrm{O}$ & 5 & 5 & 21.7 \\
\hline \multicolumn{11}{|l|}{ Development } \\
\hline Crown-Only & $\mathrm{O}$ & $\mathrm{O}$ & $\mathrm{O}$ & $\mathrm{O}$ & $\mathrm{O}$ & $\mathrm{O}$ & $\mathrm{O}$ & 5 & 5 & 21.7 \\
\hline Partial Root & O & $\mathrm{O}$ & $\mathrm{O}$ & $\mathrm{O}$ & $\mathrm{O}$ & o & $\mathrm{O}$ & o & O & 0.0 \\
\hline Fully Formed & 5 & 1 & 4 & $\mathrm{O}$ & 3 & 3 & 2 & $\mathrm{O}$ & 18 & 78.3 \\
\hline
\end{tabular}

The supernumeraries ( $\mathrm{n}=23)$ included 8 conical, 5 tuberculate, and 10 supplemental teeth; two of the 3 supernumerary mandibular canines were conical and one was supplemental, all of the 6 mesiodentes were conical, all distomolars were tuberculate and all maxillary lateral incisors and premolars were supplemental. In terms of development, 5 (21.7\%) displayed only a crown and 17 (78.3\%) were fully formed teeth. All distomolars displayed crown formation only.

Six misodentes were found in the study sample, five in the maxilla and one in the mandible. All maxillary mesiodens were conical and fully formed. Three of the maxillary mesiodentes were impacted and two were erupted. Two mesiodentes were horizontal and two were located transverse to the sagittal plane of the maxilla while one mesiodens was mesioinclined. Supernumerary laterals were three cases; two cases were in males and one in a female. All supernumerary laterals $(n=4)$ were supplemental, erupted, vertical and fullyformed.

Distomolars were four cases, three were in males and one in a female, all cases were located in maxilla. All were vertical, tubercular, impacted and had the crown only formed. Parapremolars were five teeth and all were in three males, two cases were located in the mandible and one in the maxilla. All maxillary parapremolars were supplemental, erupted, vertical and fully-formed. One of the mandibular premolars was mesioangular and the other was distoangular, both were supplemental, impacted and fully-formed.

\section{Discussion}

The etiology of supernumerary teeth is not clearly understood. A number of theories have been postulated to explain their occurrence; these include the atavism theory, dichotomy theory and dental lamina hyperactivity theory. The atavism theory suggests that the development of supernumerary teeth is a result of phylogenetic reversion to extinct primates with three pairs of incisors, a theory that has been discarded by embryologists. The dichotomy theory suggests that supernumerary teeth are a result of a dichotomy of the tooth bud into two equal or different-sized parts, resulting in the formation of two teeth of equal size, or one normal and one dysmorphic tooth, respectively. Yet, the most supported theory is the dental lamina hyperactivity theory, which suggests that supernumerary teeth are formed as a result of local, independent, conditioned hyperactivity of the dental lamina that develops into an extra tooth bud, which results in a supernumerary tooth. 
Genetics is also thought to contribute to the development of supernumerary teeth, as such teeth have been reported in twins, siblings and sequential generations of a single-family. The interplay between genetic and environmental influences during the process of odontogenesis can lead to a range of anomalies of tooth number and size, including hypodontia, supernumerary teeth, microdontia and macrodontia [20-22]. Environmental influences such as trauma, infections, radiation, drugs, and hormonal influences have been suggested as possible insults that might have impinged on tooth formation during the embryologic stages of dental development [23].

Most supernumerary teeth are single; the presence of multiple impacted or erupted supernumerary teeth is rare and mostly is associated with some genetic syndromes [24,25]. According to some authors, eight very different entities present supernumerary teeth as a distinctive feature [26]. These are cleidocranial dysplasia, familial adenomatous polyposis, trichorhinophalangeal syndrome type I, Rubinstein-Taybi syndrome, Nance-Horan syndrome, Opitz G/BBB syndrome, oculofaciocardiodental syndrome, Robinow syndrome. Yet, other syndromes may have supernumerary teeth among their clinical findings such as Apert, Crouzon, Kreiborg-Pakistani, Ellisvan Creveld, Goldenhar, Noonan [26].

The prevalence of supernumerary teeth in the permanent dentition in various populations was reported to be 0.04 to $2.4 \%[4,5,7,9,10,27]$. A prevalence of $0.9 \%$ for supernumerary teeth was reported among Italian patients [4]. However, in the Turkish population, a prevalence of $0.98 \%$ for permanent supernumerary teeth was found [9]. Among Saudi individuals the prevalence was 1\% [7], Syria 1.2\% [10] and Iran 2.4\% [5]. In our study, the prevalence of supernumerary teeth was $0.86 \%$, which was in the range reported previously.

In the present study, males were more frequently affected than females in the ratio of 3.25:1, which was close to a previously reported ratio (3.1:1) [35]. However, the ratio reported in the present study is higher than other previously reported ratios [4,7,9,10,15,17-19,28-33]. Nevertheless, higher ratios of 6.5:1 [8] and 7.2:1 [34] have been reported in the literature. The variations in the gender ratios can be attributed to racial variation, and to possible sampling differences.

In agreement with other studies [9,10,31,36], the present study found a greater number of supernumerary teeth in the maxilla $(78.2 \%)$ than in the mandible (21.7\%). Around $56.5 \%$ of the supernumeraries found in this study were located in the premaxilla. This was also in agreement with other authors [15] who reported that a total of 181 of the $200(89.6 \%)$ supernumerary teeth they investigated were located in the premaxilla. The most common site for supernumeraries was the anterior maxilla (92.5\%) region $[17]$.

In our study, $64.7 \%$ out of the 17 individuals with supernumerary teeth had a single supernumerary tooth while $35.3 \%$ had two supernumeraries. Our findings are in agreement with other authors [17], who reported that $78.3 \%$ of patients with supernumeraries to have one, $21.6 \%$ patients with two, and $2.9 \%$ with three or more supernumeraries. A previous study showed that $77 \%$ out of 152 patients investigated had one supernumerary tooth, $18.4 \%$ had two supernumeraries, and the remaining seven patients (4.6\%) had three or more supernumeraries [15].

When assessing eruption status, we found that $52.1 \%$ of the supernumerary teeth were erupted. Similar frequencies of erupted supernumerary teeth have been reported by other authors. In India, of the 45 children with supernumerary teeth, 17 (48.6\%) had erupted supernumerary teeth, 12 (34.3\%) had impacted supernumerary teeth, and $6(17.1 \%)$ had both erupted and impacted teeth. Previous authors reported that $56.36 \%(\mathrm{n}=31)$ of the supernumerary teeth they found in their study were erupted [49]. However, these finding depicts a higher rate of eruption frequency than that reported by other authors $[9,10,15,31]$. 
In many studies [33,37-41], the shape of supernumerary teeth appears conical in the permanent dentition. Nevertheless, in the present study, the supplemental form was the most (43.5\%) commonly observed because of the presence of the majority of supernumerary teeth in the premolar and maxillary lateral incisors.

The developmental stage and eruption status of supernumerary teeth are important factors for surgical management. Nearly half $(48.8 \%)$ of the supernumerary teeth in our study showed only crown formation, compared to only $20.2 \%$ that were fully formed. Higher percentages (40-60\%) of fully formed supernumeraries were reported by other studies [40,42].

The most commonly found supernumerary teeth in this study were mesiodentes and distomolars (21.7\% each). Patients with mesiodens were $0.25 \%$ of the study sample while patients with distomolars were $0.2 \%$ of the study sample. The findings of the present study were similar to those of a previous research, which reported that among 1100 supernumerary teeth found in their study population $(\mathrm{n}=111293)$, mesiodens was the most common (33.3\%) followed by distomolars (23.9\%) [43]. Similarly, another study reported that among 27 supernumeraries found in the study sample, distomolars (14.8\%) were the second most occurring supernumerary tooth after mesiodens $(44.4 \%)$ [19]. The results of the present study were also similar to those of another study, which investigated 36057 individuals for supernumerary teeth and found 147 supernumeraries in 102 patients. The study reported that mesiodens $(46.9 \%)$ were the most frequent type of supernumerary teeth followed by parapremolars (24.1\%), distomolars (18\%), paramolars (5.6\%) [37]. However, the prevalence figures of the supernumerary teeth reported in the present study differ from those reported by other studies [10,31,33,40,44].

Variations in the prevalence figures and characteristics reported for supernumerary teeth in different populations maybe due to ethnic differences, and local environmental and dietary factors. In addition, the sampling criteria, diagnostic tools, and age groups might contribute to the variations reported.

Treatment of supernumerary teeth depends on the respective case and their management should be part of a comprehensive treatment plan and should not be considered in isolation. In general, supernumerary teeth are removed if any complications are identified. Hence, where the supernumerary tooth causes no esthetic or occlusal disturbance in the arch and not associated with complications it is sometimes best to leave them in place but kept under observation [20].

The optimal time for surgical intervention, however, remains contentious [12,45]. Those who advocate the immediate removal of the supernumerary tooth upon diagnosis argue that it would prevent space loss by taking advantage of the spontaneous eruptive potential of the unerupted teeth, which may help avoid extensive orthodontic and surgical treatment especially in the premaxilla [13,37,39]. The drawback of this approach is that apart from compromising the vitality of the associated permanent tooth, it can adversely affect child psychology with the development of fear towards dentistry [46]. On the other hand, those who advocate the delayed approach postpone the removal of the supernumerary tooth after the completion of root formation of the adjacent tooth. Postponing and waiting for the root development of the adjacent teeth may help preventing the loss of vitality or malformation of adjacent teeth. However, this method is associated with loss of eruptive forces of adjacent teeth; cyst formation; space loss; crowding of arch, midline shift and failure of self-correction of the displaced teeth. Thus, a significant delay in treatment can create the need for more complex surgical and orthodontic management [47].

Although this study may not represent the Palestinian population as a whole, the results are useful for primary health workers because the patients studied represent the range of dental patients presenting to the students' clinics of The Arab American University in Palestine. The findings from this study will form part of 
the baseline data for oral health in Palestine. Therefore, it is recommended that further studies be carried out on more representative samples of both the public and the private sector patients.

\section{Conclusion}

The prevalence of supernumerary teeth in the sample of the Palestinian community is low and comparable to similar previous studies. Males were affected more commonly than the females. Most supernumeraries were single, located in the anterior maxilla and are classified as mesiodens. In most cases, the supernumerary teeth were supplemental, erupted, vertical and were fully formed.

\section{Authors' Contributions}

\begin{tabular}{|c|c|c|}
\hline NZA & (iD) $0000-0001-5961-6975$ & Conceptualization, Methodology, Investigation, Formal Analysis, Writing, \\
\hline $\mathrm{AAA}$ & $\mathrm{OO}-0002-2295-162 \mathrm{X}$ & Resources, Methodology. Formal Analysis, and Writino-Review and Editing. \\
\hline $\mathrm{SM}$ & (iD) $0000-0001-7278-6960$ & $\begin{array}{l}\text { Conceptualization, Methodology, Formal Analysis, and Writing-Review and } \\
\text { Editing. }\end{array}$ \\
\hline
\end{tabular}

\section{Financial Support}

None.

\section{Conflict of Interest}

The authors declare no conflicts of interest.

\section{References}

[1] Bäckman B, Wahlin YB. Variations in number and morphology of permanent teeth in 7-year-old Swedish children. Int J Paediatr Dent 2001; 11(1):1 1-7. https://doi.org/10.1046/j.1365-263x.2001.00205.x

[2] Fekonja A. Prevalence of dental developmental anomalies of permanent teeth in children and their influence on esthetics. J Esthet Restor Dent 2017; 29(4):276-83. https://doi.org/10.1111/jerd.12302

[3] Costa Pinho TM, Figueiredo Pollmann MC. Study of the frequency and the features of supranumerary teeth found in one Portuguese population. Bull Group Int Rech Sci Stomatol Odontol 2004; 46(2-3):52-62.

[4] Laganà G, Venza N, Borzabadi-Farahani A, Fabi F, Danesi C, Cozza P. Dental anomalies: prevalence and associations between them in a large sample of non-orthodontic subjects, a cross-sectional study. BMC Oral Health 2017; 17(1):62. https://doi.org/10.1186/s12903-017-0352-y

[5] Shokri A, Poorolajal J, Khajeh S, Faramarzi F, Kahnamoui HM. Prevalence of dental anomalies among 7- to 35-yearold people in Hamadan, Iran in 2012-2013 as observed using panoramic radiographs. Imaging Sci Dent 2014; 44(1):713. https://doi.org/10.5624/isd.2014.44.1.7

[6] Hagiwara Y, Uehara T, Narita T, Tsutsumi H, Nakabayashi S, Araki M. Prevalence and distribution of anomalies of permanent dentition in 9584 Japanese high school students. Odontology 2016; 104(3):380-9. https://doi.org/10.1007/s10266-015-0225-2

[7] Vani NV, Saleh SM, Tubaigy FM, Idris AM. Prevalence of developmental dental anomalies among adult population of Jazan, Saudi Arabia. Saudi J Dent Res 2016; 7(1):29-33. https://doi.org/10.1016/j.sjdr.2015.03.003

[8] Davis PJ. Hypodontia and hyperdontia of permanent teeth in Hong Kong schoolchildren. Community Dent Oral Epidemiol 1987; 15(4):218-20. https://doi.org/10.1111/j.1600-0528.1987.tb00524.x

[9] Arikan V, Ozgul BM, Oz FT. Prevalence and characteristics of supernumerary teeth in a child population from Central Anatolia - Turkey. Oral Health Dent Manag 2013; 12(4):269-72.

[10] Burhan AS, Nawaya FR, Arabi Katbi ME, Al-Jawabra AS. Prevalence of supernumerary teeth in a nonsyndromic Syrian sample. J Egypt Public Health Assoc 2015; 90(4):146-9.

https://doi.org/10.1097/01.EPX.0000475614.20865.db

[11] Scheiner MA, Sampson WJ. Supernumerary teeth: a review of the literature and four case reports. Aust Dent J 1997; 4Q2(3):160-5. https://doi.org/10.1111/j.1834-7819.1997.tbo0114.x 
[12] Ata-Ali F, Ata-Ali J, Peñarrocha-Oltra D, Peñarrocha-Diago M. Prevalence, etiology, diagnosis, treatment and complications of supernumerary teeth. J Clin Exp Dent 2014; 6(4):e414-418. https://doi.org/10.4317/jced.51499

[13] Primosch RE. Anterior supernumerary teeth - assessment and surgical intervention in children. Pediatr Dent 1981; $3(2): 204-15$.

[14] Mallineni SK. Supernumerary teeth: review of the literature with recent updates. Conf Pap Sci 2014; $2014: 764050$. https://doi.org/10.1155/2014/764050

[15] Rajab LD, Hamdan MA. Supernumerary teeth: review of the literature and a survey of 152 cases. Int J Paediatr Dent 2002; 12(4):244-54. https://doi.org/10.1046/j.1365-263x.2002.00366.x

[16] Syriac G, Joseph E, Rupesh S, Philip J, Cherian SA, Mathew J. Prevalence, characteristics, and complications of supernumerary teeth in nonsyndromic pediatric population of South India: a clinical and radiographic study. J Pharm Bioallied Sci 2017; 9(Suppl 1):S231-S236. https://doi.org/10.4103/jpbs.JPBS_154_17

[17] Yassin SM. Prevalence and distribution of selected dental anomalies among saudi children in Abha, Saudi Arabia. J Clin Exp Dent 2016; 8(5):e485-e490. https://doi.org/10.4317/jced.52870

[18] Chou ST, Chang HP, Yang YH, Lung CY, Tseng YC, Pan CY, et al. Characteristics of supernumerary teeth among nonsyndromic dental patients. J Dent Sci 2015; 10(2):133-8. https://doi.org/10.1016/j.jds.2013.12.004

[19] Mahabob MN, Anbuselvan GJ, Kumar BS, Raja S, Kothari S. Prevalence rate of supernumerary teeth among nonsyndromic South Indian population: an analysis. J Pharm Bioallied Sci 2012; 4(Suppl 2): S373-S375. https://doi.org/10.4103/0975-7406.100279

[20] Brook AH, Griffin RC, Smith RN, Townsend GC, Kaur G, Davis GR, et al. Tooth size patterns in patients with hypodontia and supernumerary teeth. Arch Oral Biol 2009; 54(Suppl 1):S63-70.

https://doi.org/10.1016/j.archoralbio.2008.05.016

[21] Bailleul-Forestier I, Molla M, Verloes A, Berdal A. The genetic basis of inherited anomalies of the teeth. Eur J Med Genet 2008; 51(4):273-91. https://doi.org/10.1016/j.ejmg.2008.02.009

[22] Brook AH. Multilevel complex interactions between genetic, epigenetic and environmental factors in the aetiology of anomalies of dental development. Arch Oral Biol 2009; 54(Suppl 1):S3-17. https://doi.org/10.1016/j.archoralbio.2009.09.005

[23] Brook AH. A unifying aetiological explanation for anomalies of human tooth number and size. Arch Oral Biol 1984; 29(5):373-8. https://doi.org/10.1016/0003-9969(84)90163-8

[24] Lubinsky M, Kantaputra PN. Syndromes with supernumerary teeth. Am J Med Genet Part A 2016; 170(10):2611-6. https://doi.org/10.1002/ajmg.a.37763

[25] Subasioglu A, Savas S, Kucukyilmaz E, Kesim S, Yagci A, Dundar M. Genetic background of supernumerary teeth. Eur J Dent 2015; 9(1):153-8. https://doi.org/10.4103/1305-7456.149670

[26] Cammarata-scalisi F, Avenda A, Callea M. Main genetic entities associated with supernumerary teeth. Arch Argent Pediatr 2018; 116(6):437-44. https://doi.org/10.5546/aap.2018.eng.437

[27] Afify AR, Zawawi KH. The prevalence of dental anomalies in the Western region of Saudi Arabia. ISRN Dent 2012; 2012:837270. https://doi.org/10.5402/2012/837270

[28] Dobles NJ, Meza RS. Prevalence of supernumerary teeth in a mexican sample. Rev Mex Ortod 2015; 3(2):e88-e91. https://doi.org/10.1016/j.rmo.2016.03.026

[29] Anegundi R, Tegginmani V, Battepati P, Tavargeri A, Patil S, Trasad V, et al. Prevalence and characteristics of supernumerary teeth in a non-syndromic South Indian pediatric population. J Indian Soc Pedod Prev Dent 2014; 32(1):9-12. https://doi.org/10.4103/0970-4388.127041

[30] Asaumi J, Shibata Y, Yanagi Y, Hisatomi M, Matsuzaki H, Konouchi H, et al. Radiographic examination of mesiodens and their associated complications. Dentomaxillofacial Radiol 2004; 33(2):125-7. https://doi.org/10.1259/dmfr/68039278

[31] Celikoglu M, Kamak H, Oktay H. Prevalence and characteristics of supernumerary teeth in a non-syndrome Turkish population: associated pathologies and proposed treatment. Med Oral Patol Oral Cir Bucal 2010; 15(4):e575-8. https://doi.org/10.4317/medoral.15.e575

[32] Gopakumar D, Thomas J, Ranimol P, Vineet DA, Thomas S, Nair VV. Prevalence of supernumerary teeth in permanent dentition among patients attending a dental college in South Kerala: a pilot study. J Indian Acad Oral Med Radiol 2014; 26(1):42-5. https://doi.org/10.4103/0972-1363.141854

[33] Singh VP, Sharma A, Sharma S. Supernumerary teeth in Nepalese children. Scientific World Journal 2014; 2014: 215396. https://doi.org/10.1155/2014/215396

[34] Patil S, Maheshwari S. Prevalence of impacted and supernumerary teeth in the North Indian population. J Clin Exp Dent 2014; 6(2): e116-e120. https://doi.org/10.4317/jced.51284

[35] Anthonappa RP, Omer RS, King NM. Characteristics of 283 supernumerary teeth in southern Chinese children. Oral Surg Oral Med Oral Pathol Oral Radiol Endod 2008; 105(6):e48-54. https://doi.org/10.1016/j.tripleo.2008.01.035

[36] Salcido-García JF, Ledesma-Montes C, Hernández-Flores F, Diego-Pérez, Garcés-Ortíz M. Frecuencia de dientes supernumerarios en una población Mexicana. Med Oral Patol Oral Cir Bucal 2004; 9(5):403-9.

[37] Fernández Montenegro P, Valmaseda Castellón E, Berini Aytés L, Gay Escoda C. Retrospective study of 145 supernumerary teeth. Med Oral Patol Oral Cir Bucal 2006; 11(4):E339-44 
[38] Ferrés-Padró E, Prats-Armengol J, Ferrés-Amat E. A descriptive study of 113 unerupted supernumerary teeth in 79 pediatric patients in Barcelona. Med Oral Patol Oral Cir Bucal 2009; 14(3):E146-52.

[39] Gomes RR, Fonseca JAC, Paula LM, Faber J, Acevedo AC. Prevalence of hypodontia in orthodontic patients in Brasilia, Brazil. Eur J Orthod 2010; 32(3):302-6. https://doi.org/10.1093/ejo/cjp107

[40] Esenlik E, Sayin MÖ, Atilla AO, Özen T, Altun C, Başak F. Supernumerary teeth in a Turkish population. Am J Orthod Dentofac Orthop 2009; 136(6):848-52. https://doi.org/10.1016/j.ajodo.2007.10.055

[41] Küchler EC, Costa AG, Costa MC, Vieira AR, Granjeiro JM. Supernumerary teeth vary depending on gender. Braz Oral Res 2011; 25(1):76-9. https://doi.org/10.1590/S1806-83242011000100013

[42] De Oliveira Gomes C, Drummond SN, Jham BC, Abdo EN, Mesquita RA. A survey of 460 supernumerary teeth in Brazilian children and adolescents. Int J Paediatr Dent 2008; 18(2):98-106. https://doi.org/10.1111/j.1365-263X.2007.00862.x

[43] Bereket C, Çakir-Özkan N, Şener I, Bulut E, Baştan A. Analyses of 1100 supernumerary teeth in a nonsyndromic Turkish population: a retrospective multicenter study. Niger J Clin Pract 2015; 18(6):731-8. https://doi.org/10.4103/1119-3077.154213

[44] Leco Berrocal M, Morales JFM, González JMM. An observational study of the frequency of supernumerary teeth in a population of 2000 patients. Med Oral Patol Oral Cir Bucal 2007; 12(2):134-8.

[45] Batra P, Duggal R, Parkash H. Non-syndromic multiple supernumerary teeth transmitted as an autosomal dominant trait. J Oral Pathol Med 2005; 34(10):62 1-5. https://doi.org/10.1111/j.1600-0714.2005.00271.x

[46] Virk PKS, Sharma U. Management of torsiversion of a tooth secondary to a mesiodens. Indian J Dent Edu 2014; $5(1): 4-7$.

[47] Russell KA, Folwarczna MA. Mesiodens - diagnosis and management of a common supernumerary tooth. J Can Dent Assoc 2003; 69(6):362-6. 